\title{
Retrospective analysis of injury trends in recreational skiers and snowboarders in Erciyes Ski Centre
}

\author{
Özen G. ${ }^{1 \mathrm{ABCD}}$, Yilmaz E. ${ }^{2 \mathrm{ABD}}$, Koç H. ${ }^{3 \mathrm{ABD}}$, Akalan C. ${ }^{4 A C D}$ \\ ${ }^{1}$ Department of Physical Education and Sports Teaching, Faculty of Sport Sciences, Çanakkale Onsekiz Mart \\ University, Çanakkale, Turkey \\ ${ }^{2}$ Department of Sport Sciences, Faculty of Sport Sciences, Hitit University, Çorum, Turkey \\ ${ }^{3}$ Department of Coaching Education, Faculty of Sport Sciences, Çanakkale Onsekiz Mart University, Çanakkale, \\ Turkey \\ ${ }^{4}$ Department of Coaching Education, Faculty of Sport Sciences, Ankara University, Ankara, Turkey.
}

Authors' Contribution: A - Study design; B - Data collection; C - Statistical analysis; D - Manuscript Preparation; E - Funds Collection

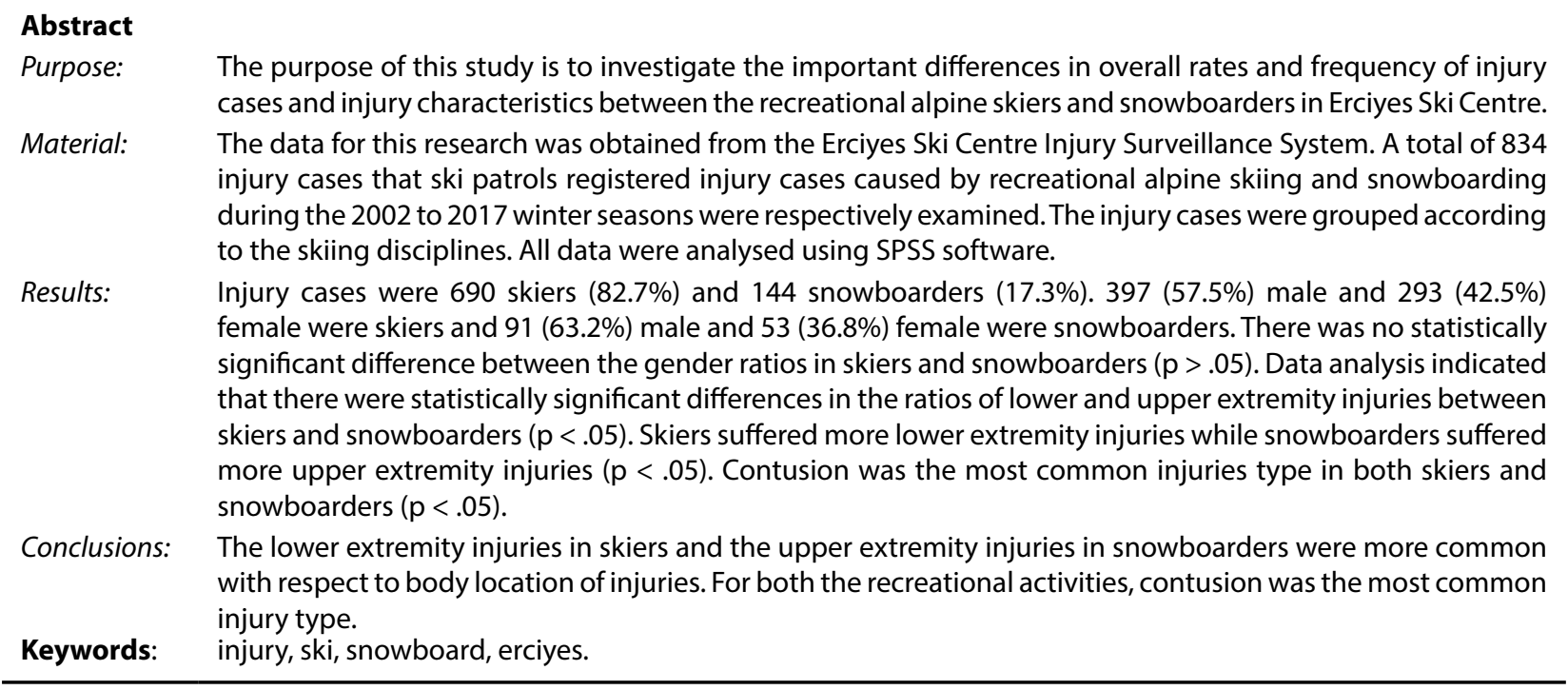

\section{Introduction}

Alpine skiing and snowboard have gained increasing worldwide popularity as both recreational activities and winter sports for the last years. However, it is well known that both activities are hazardous because it is the fact that engaging in alpine skiing and snowboarding are associated with a risk of severe injury [1]. Nowadays, the new technology ski and snowboard equipment provide the opportunity for skiing and snowboarding at the higher speed. However, the excessive speed and less skill level for both recreational alpine skiers and snowboarders are the leading cause of ski-related injuries [2,3]. Epidemiologic studies have reported that the cases of skiing injuries have increased. Moreover, these studies have shown that skiing injuries have mostly occurred for recreational alpine skiing and snowboard among children, adolescents, and adults $[4,5]$. Many people who participate in recreational skiing and snowboard every year suffer severe sportsrelated injuries such as: sprains, fractures contusions, lacerations, dislocations, and concussion [6].

Erciyes ski centre is among the most popular ski resort in both Turkey and Europe. Such as alpine skiing and snowboard, the different types of skiing are practised in Erciyes mountain slopes. The last FIS Snowboard World Cup was held in Erciyes Ski Centre. The resort

(c) Özen G., Yilmaz E., Koç H., Akalan C., 2018

doi:10.15561/18189172.2018.0606 hosted nearly two million local and foreign tourists each year. Recreational alpine ski and snowboard are the most popular activities in Erciyes. However, injury cases treated by ski patrollers on the slopes occur at a rate of 2.6 per 1000 skier-days [7]. Lately, numerous researchers have made efforts for the prevention of injuries in professional and recreational skiing and snowboarding. These researchers reported that the skiing/boarding injury rate is significantly related to instinct factors such as age, gender, skiing ability, experience and external factors such as snow, slope, weather and terrain conditions, obstacles including other skiers, high speeds, trees, poles, etc [1, 8]. Moreover, because alpine skiing and snowboarding are different skiing disciplines, it is likely that there are differences in the mechanisms of injury.

The preventing skiing injury is usually very difficult, expensive and complex, and thus, the people should have the information required to prevent the leading causes of alpine skiing and snowboarding injuries. The success of skiing injury prevention systems and applicability are dependent upon valid and reliable definitions of skiing injury according to the type of skiing. With this in mind, many comparative studies in different ski centres have been conducted investigating the injuries associated with snowboarding and alpine skiing $[9,10]$. However, there is a need for more detailed data about skiing injury characteristics and circumstances. In order to make an 
accurate inference about the skiing injuries, numerous studies suggested that it is necessary to research for different ski centre and population groups [11]. To this end, the aim of this study is to investigate the important differences in overall rates and frequency of injury cases, injury characteristics and circumstances between the recreational alpine skiers and snowboarders in Erciyes Ski Centre.

\section{Materials and Methods}

Participants. A total of 834 injured cases were recorded in Erciyes Ski Centre from 2012 to 2017. Cases were 690 skiers $(82.7 \%)$ and 144 snowboarders (17.3\%).

Procedure. This research was conducted in Erciyes Ski Centre. The data for this research was obtained from the Erciyes Ski Centre Injury Surveillance System. A total of 834 injury cases that ski patrols registered injury cases caused by recreational alpine skiing and snowboarding during the 2002 to 2017 winter seasons were respectively examined.

Data Source. A Standard form was used to record age, gender, injury characteristics and mechanism of the skiing injury. In our study, the cases were grouped according to the skiing disciplines. Group 1 comprised alpine skiers and group 2 comprised snowboarders.
Statistical Analysis. Data analyses were performed with the software package Statistical Package for the Social Sciences (SPSS, Inc, Chicago, IL, USA). Descriptive statistics are presented as mean and standard deviations. Categorical variables are presented as frequency counts, proportions, and percentages while continuous variables are presented as mean \pm standard deviation. The Chisquare or Fisher-exact test was carried out for categorical variables and considered significant when $p<.05$. The independent t-test was also used to compare mean values between skiers and snowboarders.

\section{Results}

The frequency distributions of injury cases for alpine skiers and snowboarders in each winter seasons are presented in Figure 1. No statistically significant difference was found between the injury frequency distributions of alpine skiers and snowboarders according to winter seasons $\left[\mathrm{X}^{2}(4, \mathrm{n}=834)=3.423, p=.49\right]$.

The frequency distributions of injury cases for alpine skiers and snowboarders according to gender differences are presented in Figure 2. 397 (57.5\%) male and 293 $(42.5 \%)$ female were skiers and $91(63.2 \%)$ male and $53(36.8 \%)$ female were snowboarders. There was no statistically significant difference between the gender

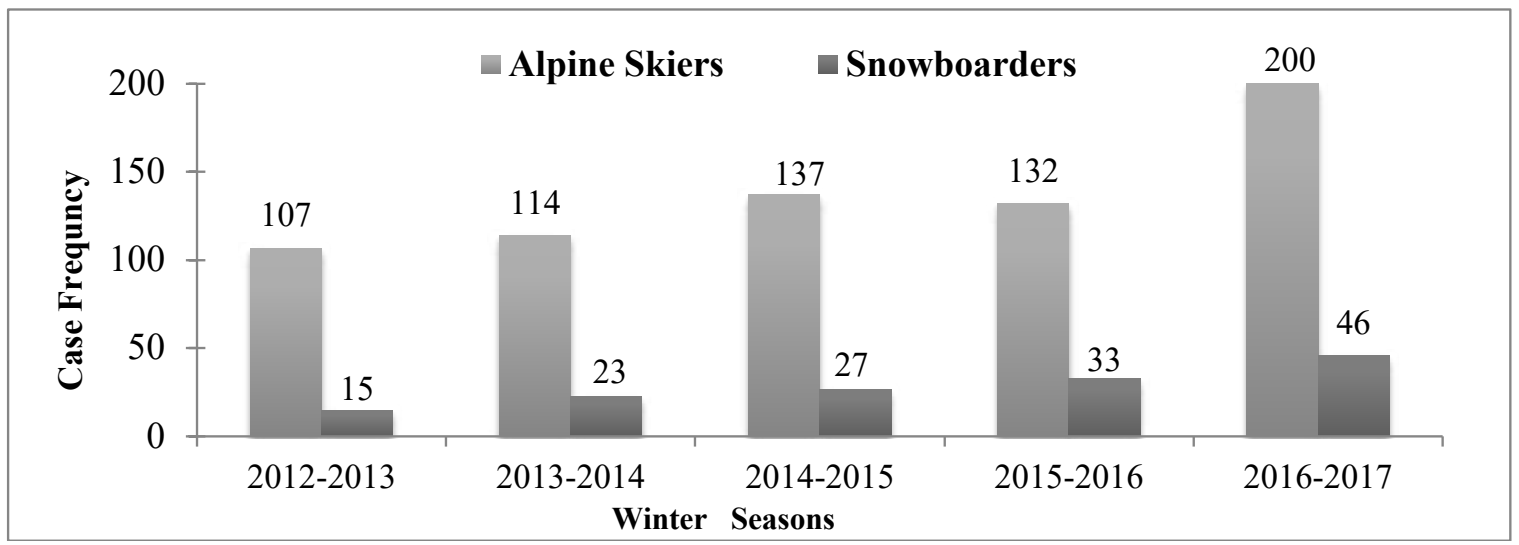

Figure 1. Injury frequency distribution for alpine skiers and snowboarders according to winter seasons.

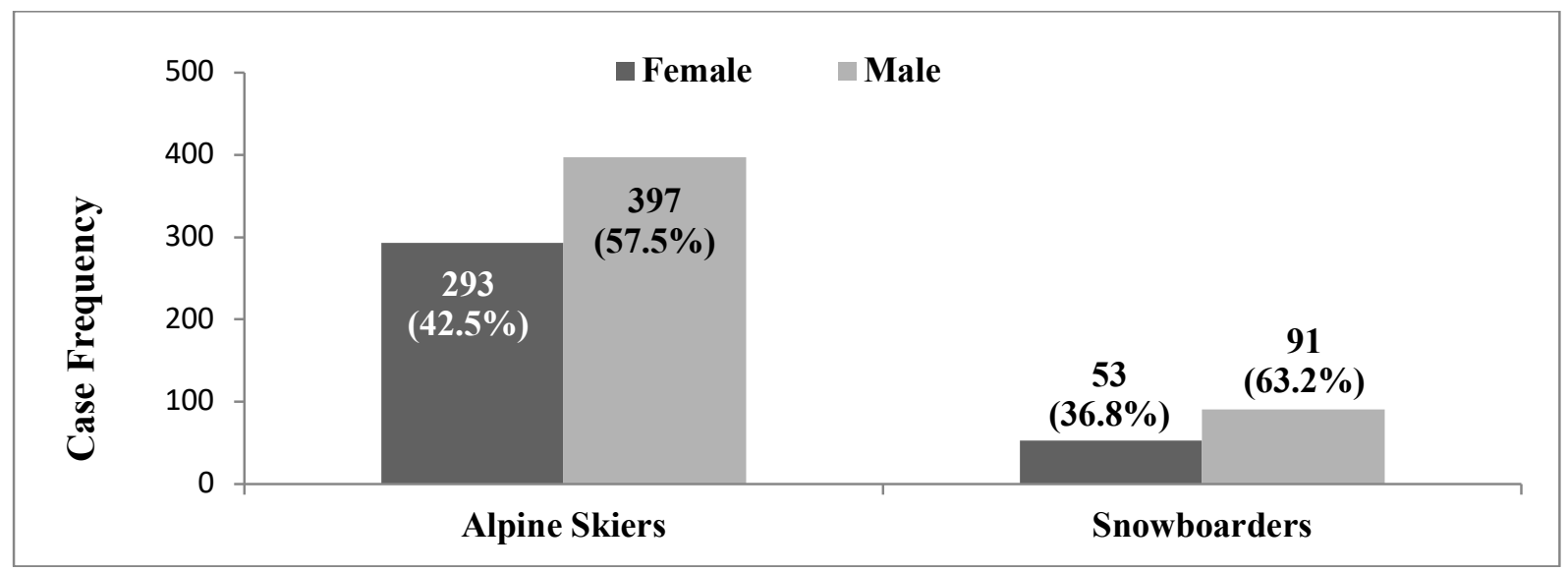

Figure 2. Injury frequency distribution for alpine skiers and snowboarders according to gender differences. 
ratios in alpine skiers and snowboarders $\left[\mathrm{X}^{2}(1, \mathrm{n}=834)\right.$ $=1.571, p=.21]$.

The comparison of the mean age between alpine skiers and snowboarders is presented in Table 1. The mean age of the injured skiers was $27.10 \pm 10.5$ years (range 6-65 years) and of the snowboarders $25.70 \pm 7.6$ years (range 10-62 years). There were no statistically significant differences in the mean age between the skiers and snowboarders $(t(832)=1.83, p=.06)$.

The frequency distributions of injury cases for alpine skiers and snowboarders according to body regions are presented in Figure 3. According to body regions, the distribution of alpine skiing injuries were $60.7 \%$ lower extremity injuries $(\mathrm{n}=419), 16.7 \%$ upper extremity injuries $(\mathrm{n}=115), 13.9 \%$ head injuries $(\mathrm{n}=96)$, and $8.7 \%$ trunk injuries $(n=60)$, respectively. The distribution of snowboarding injuries were $40.3 \%$ upper extremity injuries $(n=58), 22.2 \%$ lower extremity injuries $(n=32)$, $19.4 \%$ head injuries $(\mathrm{n}=28)$, and $18.1 \%$ trunk injuries $(n=26)$ respectively. Statistical analysis indicated that there were statistically significant differences in the ratios of lower and upper extremity injuries between skiers and snowboarders $(p<.05)$. Skiers suffered more the lower extremity injuries $\left[\mathrm{X}^{2}(1, \mathrm{n}=834)=71.118, p=.0001\right]$ while snowboarders suffered more the upper extremity injuries $\left[\mathrm{X}^{2}(1, \mathrm{n}=834)=44.909, p=.0001\right]$.
The type of skiing injuries distributed $54.6 \%$ contusion $(\mathrm{n}=377), 12.2 \%$ sprains $(\mathrm{n}=84), 9.3 \%$ open wound $(\mathrm{n}=$ $64), 7.4 \%$ strain $(n=51), 5.9 \%$ fracture $(n=41) 5.4 \%$ head trauma $(n=37)$, and $5.2 \%$ dislocation $(n=36)$. The type of snowboarding injuries distributed $54.9 \%$ contusion (n $=79), 9 \%$ sprains $(\mathrm{n}=13), 7.6 \%$ strain $(\mathrm{n}=11), 8.3 \%$ fracture $(n=12), 6.9 \%$ open wound $(n=10), 6.9 \%$ head trauma $(n=10)$, and $\% 6.3$ dislocation $(n=9)$. There was no statistically significant difference among the different injury types between skiers and snowboarders $\left[\mathrm{X}^{2}(6, \mathrm{n}=\right.$ $834)=6.718, p=.34]$. However contusion was the most common injuries type in both skiers and snowboarders $(p$ $<.05)$.

\section{Discussion}

The main purpose of our study was to examine the differences in the between recreational alpine skiing and snowboarding injuries. In this context, we examined differences between injury cases of recreational skiers and snowboarders in terms of age, gender, type of injury, and anatomical distribution of the injuries during the 2002 to 2017 winter seasons. During the winter seasons examined in Erciyes Ski Centre, the injury proportion of alpine skiers $(82.7 \%)$ was higher than in snowboarders $(17.3 \%)$. Like our findings, many researchers revealed that alpine skiing injury cases were higher than snowboarding injury cases in the different ski centres [12-14]. However, except

Table 1.The comparison of the mean age between groups.

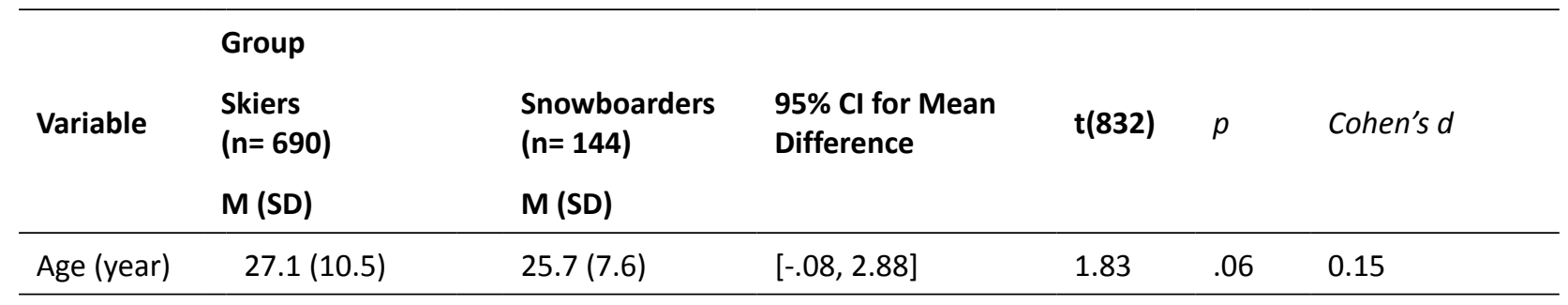

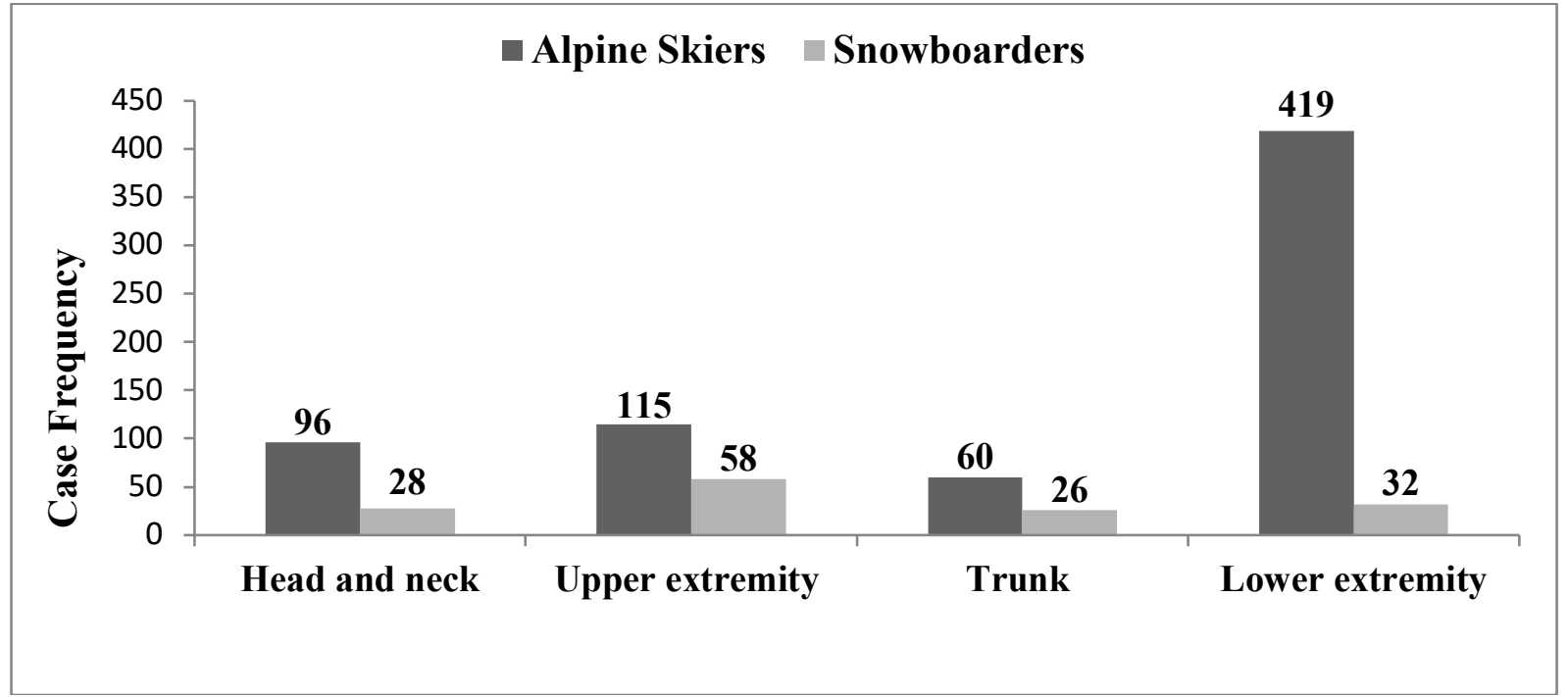

Figure 3. Injury frequency distribution for alpine skiers and snowboarders according to the body region.

(Note: * $p<.05)$ 


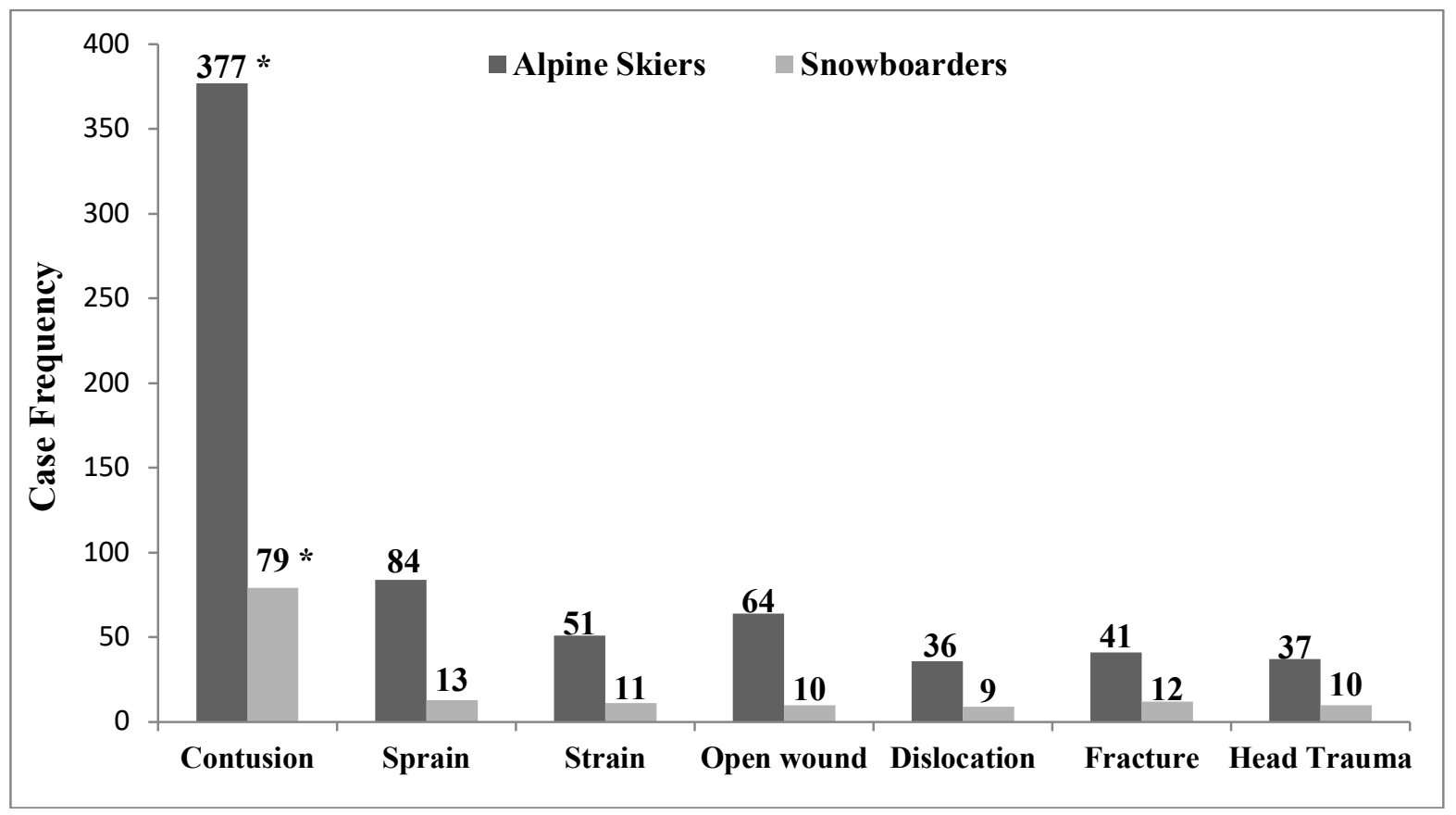

Figure 4. Injury frequency distribution for alpine skiers and snowboarders according to injury types.

for ski and snowboard races, it is not possible to determine precisely the number of skiers and snowboarder or how many times they have skiing and snowboarding in ski resorts. These injury cases have been caused probably because of the popularity of alpine skiing and the majority of participants preferred alpine skiing in the ski centres. According to winter seasons, most of the injuries occurred in alpine skiing during all seasons. Also, both alpine skiing $(29 \%)$ and snowboarding (32\%) injury cases peaked in the 2016-2017 season. However, no statistical difference was the between injury rates of skiers and snowboarders in terms of seasonally injury cases.

In this study, both injured skiers and snowboarders were mostly male. Males accounted for $57.5 \%$ of skiing and $63.2 \%$ of snowboarding injury cases. However, our finding indicated that there were no statistically significant differences between the ratio of male and female in both groups in terms of gender difference. Similar to our findings, the findings of Federiuk et al., show that injuries occurred more commonly in males both in snowboarding $(\mathrm{n}=27,87.1 \%)$ and in skiing $(\mathrm{n}=53,79.1 \%)$ [12]. Another study conducted by Ashby and Cassell, they found that of 132 injury cases male skiers were $66 \%$ and female $44 \%$ and male snowboarders were $\% 77$ and female $\% 23$ for all skiing/boarding injury cases over the period January 2004-December 2006 according to Victorian hospitalbased injury surveillance datasets [15]. Flørenes et al. have reported that there was a higher risk for males compared to females in alpine athletes [16]. Our findings are consistent with the findings of these studies with regard to the ratio of male-to-female skiing and boarding injury cases. There seems to be some evidence that male skiers have a higher amount of skiing and snowboarding injury. The number of risk factors has been specified to explain the high rate in male skiers and snowboarders; the most accepted are higher participation rate, not wearing safety equipment, and more risk-taken such as; excessive speed skiing/boarding, aggressive skiing style, and dangerous maneuvers [3,16-18].

The findings of this study revealed that injured alpine skiers $(27.10 \pm 10.5$ years $)$ appear to be at slightly older than snowboarders (25.70 \pm 7.6 years). However, statistical analysis showed no significant difference between the two groups $(p<.05)$. Previous studies of skiing/boarding injury reported that the highest injury frequencies were observed among adolescents and young adults in groups of skiers and snowboarders [15]. A similar study published by Bridges et al., who investigated the snowboarding injuries in Eastern Canada have been reported that injured snowboarders (18.3 \pm 7.0 years) were younger than injured skiers $(29.3 \pm 17.2$ years $)(\mathrm{p}<.05)[19]$. Mueller et al. (2008) stated that the higher rate of head injuries occurred 13-24 and 25-39 age groups and also the rates of using helmet were lower in these age groups [18]. A study completed by Hagel et al., who examined skiing and snowboarding injuries In Quebec has demonstrated that skiing and boarding injury cases were more common in adolescents and young adult groups [13]. Taken together, these observations and our results suggested that the injury cases of both skiing and snowboarding occurred commonly among adolescents and young skiers/boarders. Therefore, it should be paid more attention to prevent skiing/boarding injury cases in for adolescent and young people skiers/boarders.

The location of the injury on the body was examined for both the injured recreational skiers and snowboarders. Statistical analysis of our findings indicated that recreational skiers suffer mainly lower extremity injuries whereas recreational snowboarders suffer mainly upper extremity injuries $(p<.05)$. Lower extremity injuries 
were responsible for $60.7 \%$ of skiing injuries while upper extremity injuries were responsible for $40.3 \%$ of snowboarding injuries. Our results concur with those of Hagel et al., who reported that the upper extremity incidence of snowboarders was 3-4 times higher than injured skiers. On the other hand, they reported that snowboarders were less likely to injure a lower limb than alpine skiers [13]. Similarly, previous studies reported a higher likelihood of lower extremity injuries in alpine skiing and upper extremity injuries in snowboarding $[8,11,20]$. Lower extremity injuries in skiers occur more frequent because the wearing ski boot and bindings in alpine skiing restricts lower extremity range-of-motion. In alpine skiing, falling and the sudden changing of the movement direction of the lower limbs lead to an overload and overstretched of the tendons, ligaments and bones in the lower limbs thus the serious injury occurred in the lower extremity [21]. In addition, a number of researchers stated that not correctly adjusted bindings were a common cause of lower extremity injuries [22]. In this study, 79 of all the snowboarding injuries were in the upper extremity. More than half of all the reported snowboarding injuries located in the upper extremities. Snowboarders are more prone to become injured because of losing balance while riskier jumping [13]. When the snowboarders lose balance, usually snowboarders with one foot attached to the board use their hands to attempt to break the fall [10]. Therefore, it was not surprising that the upper extremity injuries occurred more likely among snowboarders.

According to the results of this study, the injured recreational alpine skiers and snowboarders were almost evenly represented in the proportions of the injury type. There was no statistically significant difference between the two groups with respect to the proportions of the injury type $(p>.05)$. However, contusion was the most common injuries observed among both the injured snowboarders and skiers $(\mathrm{p}<.05)$, accounting for $54.6 \%$ of skiing injuries and $54.9 \%$ of snowboarding injuries. Other injury types have a similar incidence rate in the groups and no statistical difference was between two groups. Contusions are one of the most common sportsrelated injuries in many sports disciplines [23]. In the alpine skiing and snowboarding, contusion usually occurs hard and icy slopes when skiers or snowboarders fall [24]. The slopes of Erciyes Ski Centre are often hard and icy during ski seasons. For this reason, contusion injuries can be expected to be more likely occurred in Erciyes Ski Centre. In addition, the least skilled and least experienced recreational skiers and snowboarders tend to ski at slow speeds and do non-aggressive turning maneuvers [25]. Therefore the contusion among the recreational skiers and snowboarders was more common the injury type than the more serious injury types such as the sprain, fracture, strain, and head trauma. However, various clinical researches have demonstrated that contusions are usually the minor health problems and will heal fastly [23].

\section{Conclusion}

As a result, in the Erciyes Ski Centre during the 2002 to 2017 winter seasons, the rates of recreational skiing and snowboarding injuries were similar. The lower extremity injuries in skiers and the upper extremity injuries in snowboarders were more common with respect to body location of injuries. For both the recreational activities, contusion was the most common injury type. An increase in balance and skiing/boarding skills would help to prevent the contusion injury in recreational skiing activities. On the other hand, educational programmes, formal instructions, and safety initiatives targeting the prevent upper extremity injuries in recreational snowboarders and lower extremity injuries in recreational alpine skiers may reduce the injury incidence. The strength of our research was the number of injuries recorded in the Erciyes Ski Centre during 5 successive winter seasons. However, the primary limitation of this retrospective research is it was not possible the obtaining data about the number of uninjured skiers and snowboarders and their sex. A major source of limitation is due to the current data system in the ski centre does not register the gender or used equipment of the skiers/snowboarders.

\section{Highlights}

- Lower extremity injuries were most common among injured recreational alpine skiers.

- Upper extremity injuries were most common among injured recreational snowboarders

- The contusion was the most common injury type in injured recreational skiers and snowboarders.

\section{Acknowledgments}

We gratefully acknowledge the help of all the participant who took part in the study.

\section{Conflict of Interest}

The authors declare that they have no conflict of interest. 


\section{References}

1. Owens BD, Nacca C, Harris AP, Feller RJ. Comprehensive review of skiing and snowboarding injuries. J Am Acad Orthop Surg. 2018; 26(1):e1-e10. https://doi.org/10.5435/JAAOS-D-16-00832

2. Flanagan T. Alpine skiing technology: faster, higher, stronger. Sports Thecnol. 2009;2(1-2):5-6. https://doi.org/10.1080/19346182.2009.9648492

3. Williams R, Delaney T, Nelson E, Gratton J, Laurent J, Heath B. Speeds associated with skiing and snowboarding. Wilderness Environ Med. 2007;18(2):102-5. https://doi.org/10.1580/06-WEME-OR-037R1.1

4. De Roulet, A, Inaba K, Strumwasser A, Chouliaras K, Lam L, Benjamin E, Grabo D, Demetriades D. Severe injuries associated with skiing and snowboarding: A national trauma databankstudy.JTraumaAcute CareSurg. 2017;82(4):781-86. https://doi.org/10.1097/TA.0000000000001358

5. Deady LH, Salonen D. Skiing and snowboarding injuries: a review with a focus on mechanism of injury. Radiol Clin North Am. 2010;48(6):1113-24. https://doi.org/10.1016/j.rcl.2010.07.005

6. Dohjima T, Sumi Y, Ohno T, Sumi H, Shimizu K. The dangers of snowboarding: a 9-year prospective comparison of snowboarding and skiing injuries. Acta Orthopaedica Scandinavica. 2001;72(6):657-60. https://doi.org/10.1080/000164701317269111

7. Ozen G, Yilmaz E, Koc H, Akalan, C. An epidemiological investigation of skiing injuries in Erciyes Ski Centre. Turk J Sports Med. 2017; 52(2):51-62. https://doi.org/10.5152/tjsm.2017.070

8. Koehle MS, Lloyd-Smith R, Taunton JE. Alpine ski injuries and their prevention. Sports Med. 2002:32(12);785-93. https://doi.org/10.2165/00007256-200232120-00003

9. Ackery A, Hagel BE, Provvidenza C, Tator CH. An international review of head and spinal cord injuries in alpine skiing and snowboarding. Inj Prev. 2007;13(6):368-75. https://doi.org/10.1136/ip.2007.017285

10.Kim S, Endres NK, Johnson RJ, Ettlinger CF, Shealy JE. Snowboarding injuries: trends over time and comparisons with alpine skiing injuries. Am J Sports Med. 2012;40(4);770-76. https://doi.org/10.1177/0363546511433279

11. Stenroos AJ, Handolin LE. Alpine skiing injuries in Finland-a two-year retrospective study based on a questionnaire among ski racers. BMC Sports Sci Med Rehabil. 2014;6(1):9. https://doi.org/10.1186/2052-1847-6-9

12.Federiuk CS, Schlueter JL, Adams AL. Skiing, snowboarding, and sledding injuries in a northwestern state. Wilderness Environ Med. 2002;13(4):245-49. https://doi.org/10.1580/1080-6032(2002)013[0245:SSASII] 2.0.CO;2
13.HagelBE, GouletC,PlattRW,PlessIB.Injuriesamongskiersand snowboarders in Quebec. Epidemiology, 2004:15(3); 279-86. https://doi.org/10.1097/01.ede.0000120044.62029.b4

14. Sulheim S, Holme I, Ekeland A, Bahr R. Helmet use and risk of head injuries in alpine skiers and snowboarders. Jama. 2006:295(8);919-24. https://doi.org/10.1001/jama.295.8.919

15.Ashby K, Cassell E. Injury in snow and ice sports. Hazard. 2007:66,1-19.

16.Flørenes TW, Bere T, Nordsletten L, Heir S, Bahr R. Injuries among male and female World Cup alpine skiers. $B r \quad J$ Sports Med. 2009;43(13):973-978. https://doi.org/10.1136/bjsm.2009.068759

17.Brunner F, Ruedl G, Kopp M, Burtscher M. Factors associated with the perception of speed among recreational skiers. PloS One. 2015;10(6):e0132002. https://doi.org/10.1371/journal.pone.0132002

18. Mueller BA, Cummings P, Rivara FP, et al. Injuries of the head, face, and neck in relation to ski helmet use. Epidemiology. 2008;19:270-6. https://doi.org/10.1097/EDE.0b013e318163567c

19.Bridges EJ, Rouah F, Johnston KM. Snowblading injuries in eastern Canada. Br J Sports Med. 2003;37(6):511-15. https://doi.org/10.1136/bjsm.37.6.511

20.Coury T, Napoli AM, Wilson M, Daniels J, Murray R, Milzman, D. Injury patterns in recreational alpine skiing and snowboarding at a mountainside clinic. Wilderness Environ Med. 2013;24(4):417-21. https://doi.org/10.1016/j.wem.2013.07.002

21.Mayr HO, Cheze L. The knee injuries in skiing: Mechanisms and assessment. In Floren Colloud, Mathieu Domalain, Tony Monnet (Eds.). 33rd International Conference on Biomechanics in Sports. 2018 June 29 - July 3; Poitiers. France: 2015. P. 1357-60.

22.Bouter LM, Knipschild PG, Volovics A. Binding function in relation to injury risk in downhill skiing. Am $J$ Sports Med. 1989;17(2):226-33. https://doi.org/10.1177/036354658901700213

23.Best TM. Soft-tissue injuries and muscle tears. Clin Sports Med. 1997;16(3):419-34. https://doi.org/10.1016/S0278-5919(05)70033-8

24.Spörri J, Kröll J, Gilgien M, Müller E. How to prevent injuries in alpine ski racing: what do we know and where do we go from here?. Sports Med. 2017;47(4):599-614. https://doi.org/10.1007/s40279-016-0601-2

25.Brooks MA, Evans MD, Rivara FP. Evaluation of skiing and snowboarding injuries sustained in terrain parks versus traditional slopes. Injury Prevention, 2010;16(2):119-22. https://doi.org/10.1136/ip.2009.022608 


\section{Information about the authors:}

Özen G.; (Corresponding author); http://orcid.org/0000-0001-5756-653X; gokmenozen44@gmail.com; Department of Physical Education and Sport Teaching, Faculty of Sport Sciences, Çanakkale Onsekiz Mart University; 17020, Çanakkale, Turkey.

Yılmaz E.; http://orcid.org/0000-0002-7822-9193; apeksakademispor@hotmail.com; Department of Sport Sciences, Faculty of Sport Sciences, Hitit University; 19030, Corum,Turkey.

Koç H.; http://orcid.org/0000-0003-2867-9775; hurmuzkoc@gmail.com; Department of Coaching Education, Faculty of Sport Sciences, Çanakkale Onsekiz Mart University; 17020, Çanakkale,Turkey.

Akalan C.; http://orcid.org/0000-0001-7669-3358; cengizakalan@gmail.com; Department of Coaching Education, Faculty of Sport Sciences, Ankara University; 06830, Ankara,Turkey.

Cite this article as: Özen G, Yilmaz E, Koç H, Akalan C. Retrospective analysis of injury trends in recreational skiers and snowboarders in Erciyes Ski Centre. Pedagogics, psychology, medical-biological problems of physical training and sports, 2018;22(6):313-319. https://doi.org/10.15561/18189172.2018.0606

The electronic version of this article is the complete one and can be found online at: http://www.sportpedagogy.org.ua/index.php/PPS/issue/archive

This is an Open Access article distributed under the terms of the Creative Commons Attribution License, which permits unrestricted use, distribution, and reproduction in any medium, provided the original work is properly cited (http://creativecommons.org/licenses/by/4.0/deed.en).

Received: 05.09.2018

Accepted: 15.10.2018; Published: 22.12.2018 